\title{
Particulate matter pollution in African cities
}

\author{
Elisaveta P. Petkova - Darby W. Jack • \\ Nicole H. Volavka-Close $•$ Patrick L. Kinney
}

Received: 13 March 2013 / Accepted: 11 June 2013 / Published online: 26 June 2013

(C) Springer Science+Business Media Dordrecht 2013

\begin{abstract}
Rapid urban population growth, air pollution emissions, and changing patterns of disease in African cities may increase the burden of air pollution-related morbidity and mortality in coming decades. Yet, air monitoring is limited across the continent and many countries lack air quality standards. This paper focuses on particulate matter (PM) pollution, one of the most relevant and widely used indicators of urban air quality. We provide an overview of published PM monitoring studies in Africa, outline major themes, point out data gaps, and discuss strategies for addressing particulate air pollution in rapidly growing African cities. Our review reveals that, although few studies have reported annual mean levels of coarse and fine particles, collective evidence from short- and long-term air monitoring studies across urban Africa demonstrates that pollution levels often exceed international guidelines. Furthermore, pollution levels may be rising as a result of increased motor vehicle traffic building on already high background concentrations of PM in many locations due to
\end{abstract}

Electronic supplementary material The online version of this article (doi:10.1007/s11869-013-0199-6) contains supplementary material, which is available to authorized users.

E. P. Petkova $(\varangle) \cdot$ D. W. Jack $\cdot$ P. L. Kinney

Department of Environmental Health Sciences,

Mailman School of Public Health, Columbia University,

722 West 168th St, New York, NY 10032, USA

e-mail: epp2109@columbia.edu

D. W. Jack

e-mail: dj2183@columbia.edu

P. L. Kinney

e-mail: plk3@columbia.edu

N. H. Volavka-Close

Center for Sustainable Urban Development, Earth Institute,

Columbia University, 475 Riverside Drive, Suite 520,

New York, NY 10115, USA

e-mail: nvolavka@ei.columbia.edu climatic and geographic conditions. Biomass burning and industrial activities, often located in cities, further exacerbate levels of PM. Despite the health risks this situation presents, air quality programs, particularly in sub-Saharan Africa, have been stalled or discontinued in recent years. Implementation of systematic PM data collection would enable air pollutionrelated health impact assessments, the development of strategies to reduce the air pollution health burden, and facilitate urban planning and transportation policy as it relates to air quality and health.

Keywords Urban air quality · Environmental health · Particulate matter $\cdot \mathrm{PM}_{10} \cdot \mathrm{PM}_{2.5} \cdot$ Africa

\section{Introduction}

Africa currently has the fastest growing population in the world, projected to more than double between 2010 and 2050, surpassing two billion (UN 2011). By 2050, nearly $60 \%$ of the population of Africa is predicted to be living in cities, compared to less than $40 \%$ in 2011 (UN 2012). Urbanization, coupled with increased industrialization, growing ownership of motor vehicles, and continued use of biomass as domestic energy source, may lead to substantial worsening of air quality across the continent. Urbanization is also a powerful driver of the global demographic and epidemiologic transition, characterized by declining birth rates, increasing life expectancy, and a shift from traditional threats such as infectious diseases and malnutrition to chronic, noncommunicable diseases like heart disease and diabetes (Omran 1971).

Developing countries are increasingly experiencing a double burden of infectious and chronic diseases (Boutayeb 2006). This burden stems in part from living conditions in urban slums, with their poor environmental conditions and infrastructure as well as lack of access to health services (Sclar et al. 
2005; Zulu et al. 2011). Populations in slums sometimes have poorer health outcomes than their rural counterparts (Fotso 2007; Kyobutungi et al. 2008; Volavka-Close and Sclar 2010). They are also often exposed to both indoor and outdoor air pollution (Bailis et al. 2005; Barnes et al. 2005). Findings from a recent study in Accra, Ghana, indicate higher levels of air pollution in low socioeconomic status communities (Dionisio et al. 2010a). Although infectious diseases still account for the majority of deaths in African counties, they will also face the largest increases worldwide in death rates from cardiovascular disease, cancer, respiratory disease, and diabetes, according to World Health Organization (WHO) projections (de-Graft Aikins et al. 2010). Exposure to urban air pollution can lead to or exacerbate these conditions (Pope and Dockery 2006; Pearson et al. 2010).

Particulate matter (PM) pollution is the most healthrelevant indicator of urban air quality (Cohen et al. 2005) and is widely used in setting air quality guidelines worldwide. Although particle characteristics such as composition and origin may affect health impacts, particulate matter is usually classified and studied according to particle size. The earliest regulatory guidelines with regard to particulate matter pollution were set for total suspended particulate (TSP), including particles of all sizes typically between 1 and $100 \mu \mathrm{m}$ in aerodynamic diameter. As scientific evidence about the health impacts of finer particles emerged, regulatory attention has subsequently focused on inhalable particles with diameters less than $10 \mu \mathrm{m}\left(\mathrm{PM}_{10}\right)$, "fine" particles with diameter less than $2.5 \mu \mathrm{m}\left(\mathrm{PM}_{2.5}\right)$, and lately on "ultrafine" particles with diameter of $0.1 \mu \mathrm{m}$ or less. Particulate matter with other sizes, for example with diameter less than $1 \mu \mathrm{m}\left(\mathrm{PM}_{1}\right)$ is also reported, albeit less frequently. Smaller particles tend to deposit more in the lungs, where they can penetrate tissue or be absorbed directly into bloodstream.

A substantial body of evidence from both developed and developing countries has established that particulate matter causes a wide range of short- and long-term adverse health effects. Two large prospective cohort studies, the Harvard Six Cities Study (Dockery et al. 1993) and the American Cancer Society (ACS) Study (Pope et al. 1995), provide the foundation for current US and WHO particulate pollution standards or guidelines. Both studies reported a robust association between long-term exposure to $\mathrm{PM}_{2.5}$ and adult premature mortality from all causes as well as cardiopulmonary diseases. The overall findings were confirmed in subsequent reanalysis of the data (Krewski et al. 2004; HEI 2000). The latest results from the ACS study that were prospectively followed for 26 years between 1982 and 2008 also demonstrated an increase in lung cancer mortality (Turner et al. 2011). Short-term exposure to $\mathrm{PM}_{2.5}$ was also found to result in increased risk for cardiovascular and respiratory hospital admissions (Dominici et al. 2006).
The latest air quality guidelines set by the WHO for mean annual exposures to $\mathrm{PM}_{2.5}$ and $\mathrm{PM}_{10}$ are 10 and $20 \mu \mathrm{g} / \mathrm{m}^{3}$, respectively. Twenty-four-hour mean values for $\mathrm{PM}_{2.5}$ and $\mathrm{PM}_{10}$ are 25 and $50 \mu \mathrm{g} / \mathrm{m}^{3}$, respectively (WHO 2006). WHO also sets interim targets that countries are encouraged to gradually achieve through enforcing stringent air quality control practices. Since such guidelines are not established in many African countries, the WHO guidelines provide a useful point of reference in analyzing the evidence for particulate matter pollution in the continent.

In this paper, we first review PM air monitoring studies in Africa in order to assess how reported data compare to international air quality guidelines. We restricted this review to studies published in peer-reviewed journals. We outline major themes, identify monitoring needs, and suggest ways to address these needs in future studies. We conclude with the evidence of PM pollution in Africa in the context of international air quality guidelines and a discussion of possible strategies for addressing current and future challenges.

\section{Literature review methods}

Literature searches were performed in English in the PubMed, Medline-OVID, SciVerse Scopus, and ISI Web of Knowledge databases. Search keywords included particulate matter, $\mathrm{PM}, \mathrm{PM}_{2.5}, \mathrm{PM}_{10}$, TSP, particulates, air pollution, outdoor air, air monitoring, and Africa, as well as the names of the African regions and each individual African country. All retrieved publications were imported to RefWorks, where duplicates were eliminated. Relevant publications were manually selected from the resulting list. Since some studies may have not been electronically indexed, additional references were also identified from the bibliographies of all selected publications. The selection was restricted to the following: (1) published in peer-reviewed English or French language journals; (2) articles containing $\mathrm{PM}_{2.5}$, $\mathrm{PM}_{10}$, or TSP monitoring data; and (3) primary articles, as well as secondary or review articles that present or refer to identifiable PM monitoring data. If not available in a better format, presented data were downloaded from charts. Articles in which methodology or data reporting were ambiguous were excluded from the selection.

\section{Context and sources of PM pollution in Africa}

The African continent encompasses diverse climatic regions. Northern Africa has an arid climate dominated by the Sahara, the largest desert in the world. The Sahel, a semiarid transitional area below the Sahara, separates the desert from the savanna and tropical rainforest regions that span across Middle, Eastern, and Western Africa. The annual cyclical 
movement of the Intertropical Convergence Zone around the equator, where northern and southern winds converge, affects rainfall in tropical and subtropical regions (Giannini et al. 2008). As a result, many African countries have pronounced dry and wet seasons.

Africa's diverse climate exerts a strong influence on PM levels. For example, in countries that experience wet and dry seasons, there is a pronounced seasonal fluctuation in particulate matter levels, with higher levels during the dry season. North Africa is one of the world's major dust-emitting regions (Engelstaedtera et al. 2006) leading to high background levels (Safar and Labib 2010). Studies reported soil dust as the main source of the $\mathrm{PM}_{2.5}$ particles collected in Ouagadougu, Burkina Faso (Boman et al. 2009), as well as in coarse particles collected in Serowe (traditional village), Selibe-Phikwe (small mining town) and Francistown (the second largest city in the country), all in eastern Botswana (Chimidza and Moloi 2000). A comparative study across Ouagadougu, Gaborone (Botswana), and Dar es Salaam (Tanzania) that explored the intra-urban variation of TSP, $\mathrm{PM}_{10}$, and $\mathrm{PM}_{2.5}$ also concluded that soil particles were a major component in the particulate matter samples (Eliasson et al. 2009).

Particulate matter pollution on the continent is also influenced by the interplay of climatic and geographic factors with human activities. Sinha and colleagues characterized the horizontal distribution of particulate matter in savannah and desert regions in South Africa, Botswana, Mozambique, Zambia, and Namibia ${ }^{1}$ during the 2000 dry biomass burning season in the context of the SAFARI 2000 Southern African Regional Science Initiative (Sinha et al. 2003). Particulate matter was collected on Teflon filters from the UW Convair-580 research aircraft. Average total particle mass across all regions during the study period ranged from 20 to $30 \mu \mathrm{g} / \mathrm{m}^{3}$. Study regions were selected mostly away from industrial activities and thus are representative of the impact of savanna fires and domestic biomass burning (Sinha et al. 2003).

Very few long-term studies have been conducted at background sites, far removed from urban areas. A 5.5-year monitoring study of aerosol chemical composition and contributing sources took place at the Rukomechi research station, located in a national park in northern Zimbabwe (Nyanganyuraa et al. 2007). The median concentrations of fine (defined as less than $2 \mu \mathrm{m}$ ) and coarse (defined as between 2 and $10 \mu \mathrm{m})$ particles were 7.4 and $8.8 \mu \mathrm{g} / \mathrm{m}^{3}$, respectively. PM levels were substantially higher during the dry season and source contributions varied across seasons.

\footnotetext{
${ }^{1}$ Paper uses a different classification and refers to all studied regions as "southern Africa"; according to the UN classification employed for this study, two of the countries (Mozambique and Zambia) are located in Eastern Africa.
}

Biomass burning accounted for 44 and $79 \%$ of the fine PM fraction during the wet and dry seasons, respectively. Other major sources included mineral dust, sea salt, and biogenic sources.

Laakso and colleagues reported annual median concentrations of $\mathrm{PM}_{1}, \mathrm{PM}_{2.5}$, and $\mathrm{PM}_{10}$ of $9,10.5$, and $18.8 \mu \mathrm{g} / \mathrm{m}^{3}$, respectively, at a clean dry savanna background site in South Africa (Laakso et al. 2008). The seasonal variability in all fractions was less pronounced.

\section{Summary of urban PM monitoring studies}

Air monitoring is of critical importance for characterizing health risks, formulating cost-effective abatement strategies, setting and enforcing appropriate air quality standards and for healthy urban planning. Unfortunately, few African cities have air monitoring systems in place and most lack any air quality monitoring capabilities (Schwela 2006). The data that do exist are not always publicly available and/or strategically communicated, which limits public knowledge as well as effective policy making. Thus, the challenge is multifaceted. Even in the presence of air quality standards in many African countries, the lack of air monitoring data blocks enforcement. According to a World Bank report, only 5 out of 27 sub-Saharan African countries studied, Ethiopia, Ghana, Madagascar, Tanzania, and Zimbabwe, were monitoring $\mathrm{PM}_{10}$ or TSP as of 2006 (Schwela 2006). Monitoring may have been discontinued in some of these countries since then. For example, in a recently published database of outdoor air pollution in cities around the world (WHO 2013), the WHO identified nine sub-Saharan African countries in which particulate matter was monitored (Algeria, Botswana, Ghana, Madagascar, Mauritius, Nigeria, Senegal, South Africa, and Tanzania). Ethiopia and Zimbabwe which were mentioned in the World Bank report were not included in this database. Also, monitoring in at least four of the sub-Saharan African countries identified by WHO was taking place for less than 12 months/year. Routine air monitoring is also carried out in Egypt and Tunisia. The governments of a total of seven countries (Algeria, Botswana, Egypt, Madagascar, Mauritius, Senegal, South Africa, and Tunisia) have published reports of PM monitoring data (WHO 2013), not all of which were easily accessible. In recent years, some air quality programs and initiatives have been phased out in sub-Saharan Africa. For example, the Regional Air Pollution in Developing Countries and Air Pollution Information Network for Africa, both funded by the Swedish International Development Cooperation Agency, were discontinued in 2009 (Schwela D., personal communication on 24 May 2011).

PM monitoring studies were found for countries highlighted by UN subregion on the map below (Fig. 1). Studies were identified for four countries (Egypt, Algeria, Tunisia, and 
Morocco) in Northern Africa, four countries (Ethiopia, Zimbabwe, Tanzania, and Kenya) in Eastern Africa, three countries (Ghana, Burkina Faso, and Nigeria) in Western Africa, and one (South Africa) in Southern Africa. We were unable to locate studies conducted in any of the countries in Middle Africa.

Since we aimed to access how the reported values compare to WHO guidelines for $\mathrm{PM}_{10}$ and $\mathrm{PM}_{2.5}$, data are summarized by particle size and sample duration (annual, 24 h, or less than 24 h) in Figs. 2 and 3. Sample durations of less than $24 \mathrm{~h}$ were grouped together because exceedance of the 24-h limit for any duration could be associated with health risks.

\section{Northern Africa}

Reported mean PM levels in Northern Africa exceeded annual and 24-h WHO guidelines. PM levels in Cairo, Egypt, where guidelines were exceeded several fold, were particularly worrisome.

Egypt is the second most affluent country on the continent, after South Africa. Egypt's capital, Cairo, is one of the two megacities on the continent and the largest city in Africa and the Middle East. Cairo is surrounded by desert regions and sand storms are frequent in spring and fall (Robaa 2003). The climate of the city is characterized by cold and rainy winter months and hot and dry summers. Large numbers of vehicles, as well as a substantial concentration of industrial facilities, contribute to high levels of PM. Two PM monitoring networks have been established by the Egyptian environmental affairs agency in Cairo as a part of the Cairo Air Improvement Project with the support of the United States Agency for International Development (Safar and Labib 2010). Despite a downward trend, Safar and Labib reported that annual $\mathrm{PM}_{10}$ levels remain very high, in excess of $150 \mu \mathrm{g} / \mathrm{m}^{3}$ at industrial, traffic, and some residential sites (Safar and Labib 2010). In another study, Zakey et al. (2008)
Fig. 1 African countries (colored) by UN subregion for which PM monitoring studies were identified and included in this publication. A list of all studies is provided in the Supplementary Table

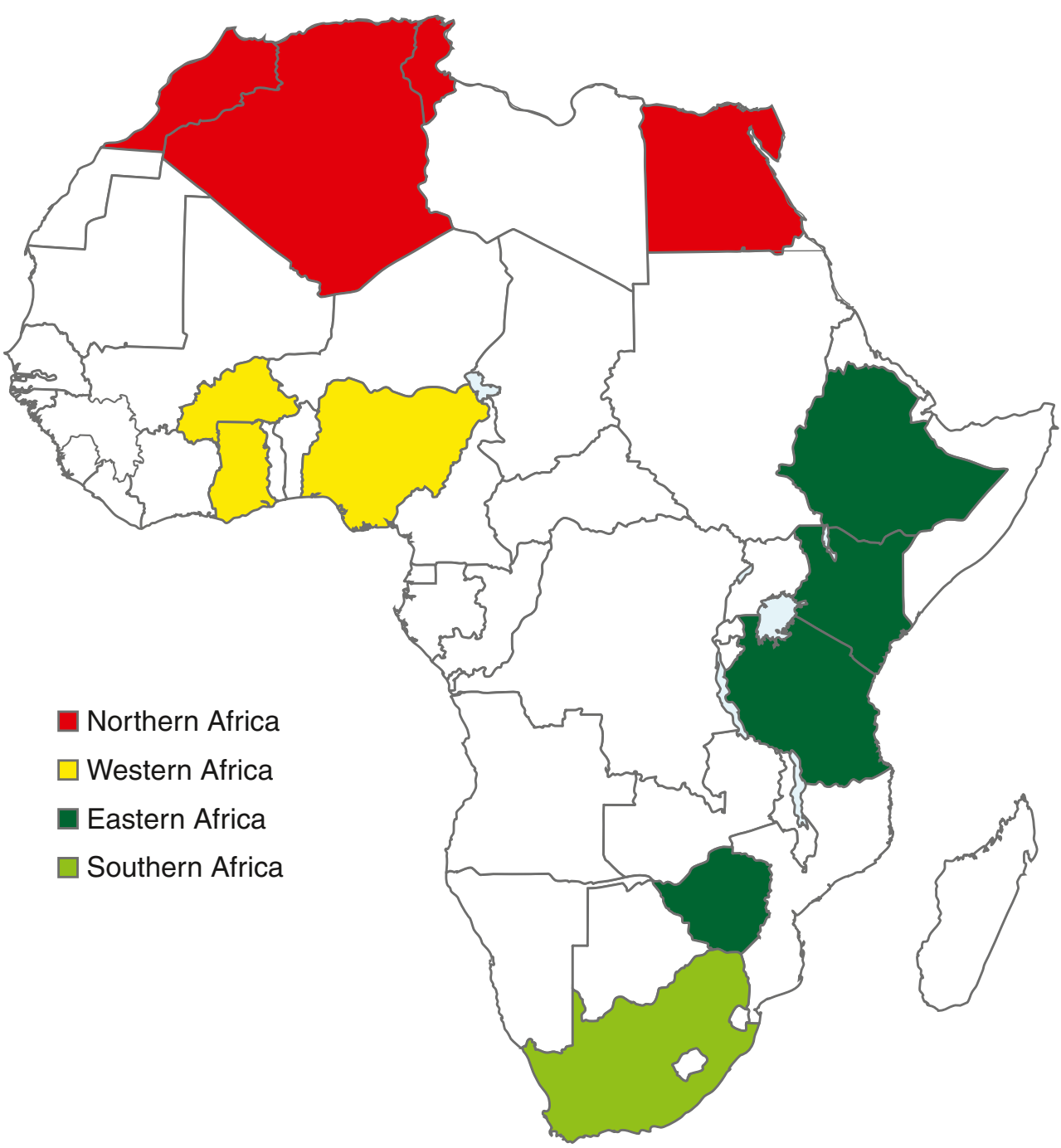


Fig. $2 \mathrm{PM}_{2.5}$ levels in African cities as reported in various studies. Green bars represent upper and lower range of means, if reported. Points represent overall mean with horizontal lines depicting standard deviation, if reported. Red vertical lines illustrate current WHO guidelines

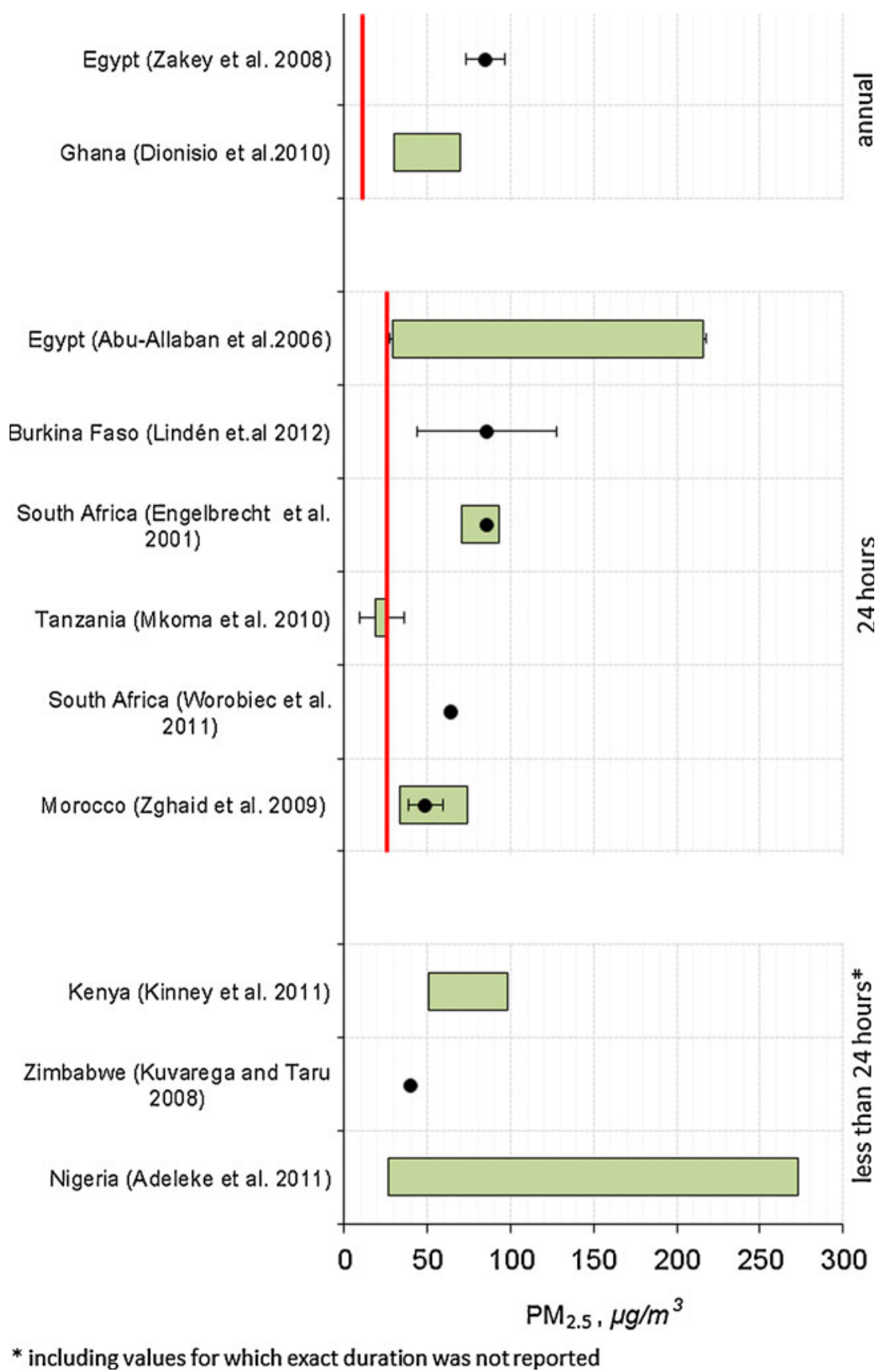

* including values for which exact duration was not reported reported annual $\mathrm{PM}_{2.5}$ and $\mathrm{PM}_{10}$ levels of $85 \pm 12$ and $170 \pm 25 \mu \mathrm{g} / \mathrm{m}^{3}$, respectively, at 17 representative sites between 2001 and 2002.

Finally, Abu-Allaban et al. (2007) collected 24-h $\mathrm{PM}_{10}$ samples at six sampling sites during monitoring campaigns in the winter and fall of 1999 and the summer of 2002. Sites were selected to represent mobile source, industrial, residential, and background exposures. Mean $\mathrm{PM}_{10}$ levels ranged from $93.0 \pm 4.8 \mu \mathrm{g} / \mathrm{m}^{3}$ at a background site to $360.3 \pm 19.2 \mu \mathrm{g} / \mathrm{m}^{3}$ at an industrial/residential site.

Overall, these studies demonstrated high levels of PM pollution in Cairo, Egypt. In addition to industrial and mobile sources, open waste burning contributed substantially to particulate matter pollution levels, particularly during the winter months.

Aoudia and Boukadoum (2005) reported data from an automated air quality monitoring network that was established in Algiers, the capital of Algeria, in 2002. Mean $\mathrm{PM}_{10}$ levels between 2002 and 2003 across the four monitoring stations ranged from approximately 38 to $129 \mu \mathrm{g} / \mathrm{m}^{3}$. The authors noted that pollution levels began rising around 7-8 am, peaked around noon, and stabilized after $5 \mathrm{pm}$. The paper concluded that while other pollutants such as $\mathrm{SO}_{2}$ and $\mathrm{NO}_{x}$ were below levels of concern, $\mathrm{PM}_{10}$ exceeded EU levels across Algiers. In a study evaluating the 


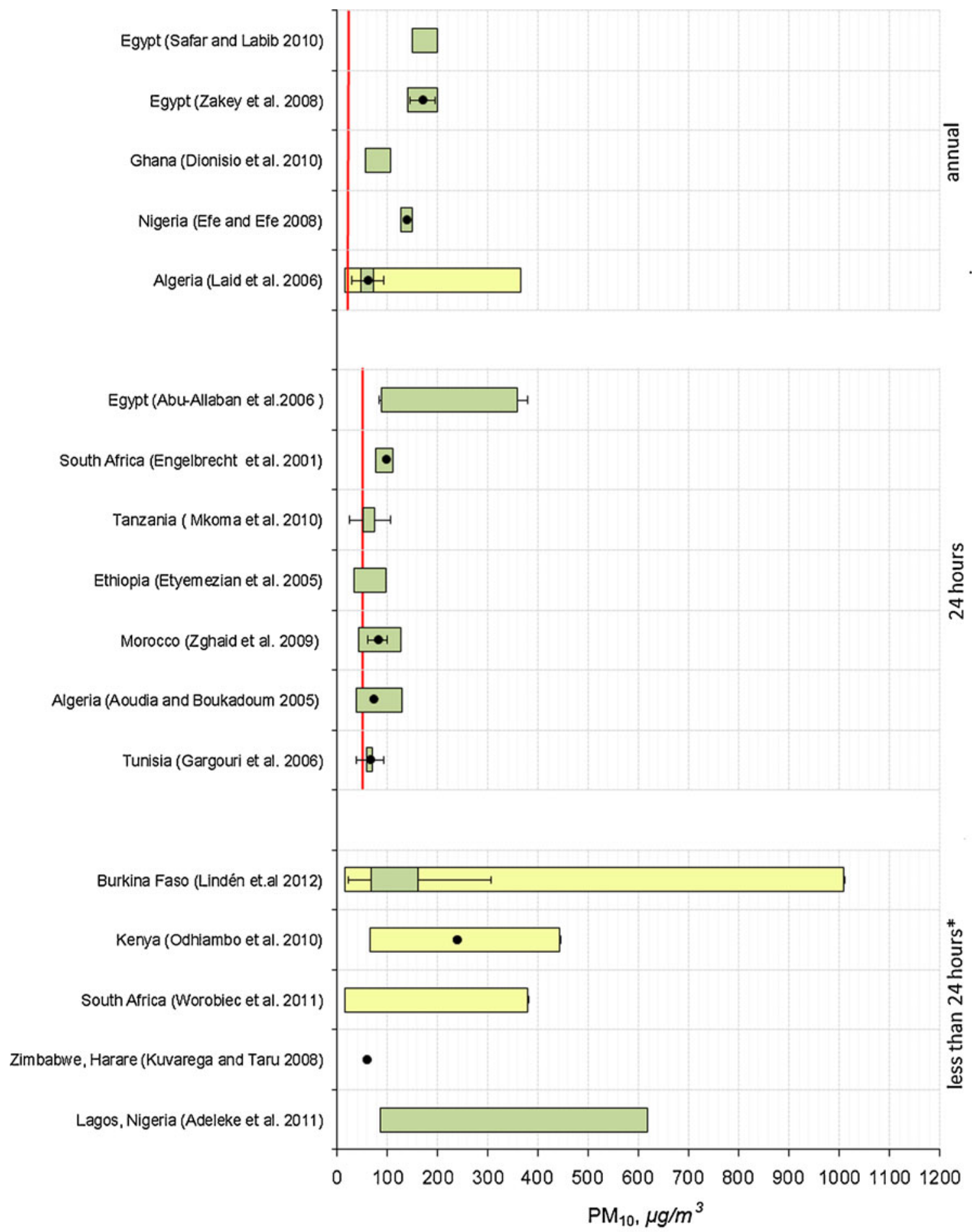

* including values for which exact duration was not reported

Fig. 3 Studies reporting $\mathrm{PM}_{10}$ data in African cities. Green bars represent upper and lower range of means, if reported. Yellow bars represent upper and lower measured value, if reported. Points represent

health effects of $\mathrm{PM}_{10}$ in Algiers, $\mathrm{PM}_{10}$ was measured at a ground station at the Centre Hospitalo-Universitaire Mustapha at Sidi-M'hamed for 1 year between 2001 and 2002. Average daily $\mathrm{PM}_{10}$ was $61 \mu \mathrm{g} / \mathrm{m}^{3}$ and was substantially higher during overall mean with horizontal lines depicting standard deviation, if reported. Red vertical lines illustrate current WHO guidelines

the winter compared to the summer, with daily averages of 74 and $48 \mu \mathrm{g} / \mathrm{m}^{3}$, respectively (Laid et al. 2006).

Ali-Khodja et al. (2008) measured TSP and particle deposition fluxes in the town of Didouche Mourad, Algeria. 
Didouche Mourad is a located in the Constantine Province with a population of little over 30,000 , in the vicinity of a cement plant. Mean TSP level was 300 or $117 \mu \mathrm{g} / \mathrm{m}^{3}$ if days with sand storms were excluded.

In Sfax, Tunisia, a 24-h mean $\mathrm{PM}_{10}$ of $66 \mu \mathrm{g} / \mathrm{m}^{3}$ was measured across the wet and dry season between October1996 and June 1997 (Gargouri et al. 2006). Sfax is a city in the south east of Tunisia with a semiarid Mediterranean climate, hot and dry in the summer and cold and wet in the winter (Azri et al. 2007). $\mathrm{PM}_{10}$ was monitored along with other pollutants at an urban station located in the vicinity of high traffic roads.

A monitoring campaign in Kenitra, Morocco, a coastal town with a population of around 400,000 people, reported a mean $\mathrm{PM}_{10}$ of $81 \mu \mathrm{g} / \mathrm{m}^{3}$ at a traffic site between June and September of 2007 (Zghaid et al. 2009). PM 10 levels rose from early June to until mid-July, stabilized in mid-July to August, and declined in September. Traffic, soil dust, and particle re-suspension were identified as major sources of particulate pollution.

\section{Western Africa}

In Western Africa, reported mean PM levels were also found to exceed the annual and 24-h WHO guidelines. PM levels were particularly high in Nigeria, although very high levels were also recorded in Burkina Faso, as well as among populations of lower socioeconomic status in Ghana.

Lagos, Nigeria, is Africa's second megacity with a population of over 20 million according to the Lagos State Department. The city has a tropical climate characterized by alternating wet and dry seasons. Air pollution in Lagos due to high traffic density and other anthropogenic factors has been of concern since the early 1990s when an air monitoring station was set up as a part of a joint project between Nigeria, Germany, and the UK (Baumbach et al. 1995). Baumbach and colleagues reported that air pollution in the city was most severe in high traffic areas. In addition, on days with Harmattan winds, daily TSP levels have been documented to increase up to tenfold to approximately $800 \mu \mathrm{g} / \mathrm{m}^{3}$. As a part of a health impact assessment study, Adeleke et al. performed 5 months of integrated sampling and reported extremely high levels up to $272.8,617.4$, and $1171.7 \mu \mathrm{g} / \mathrm{m}^{3}$ for $\mathrm{PM}_{2.5}, \mathrm{PM}_{10}$, and TSP, respectively (Adeleke et al. 2011). In comparison, mean annual $\mathrm{PM}_{10}$ levels of $126.5 \mu \mathrm{g} / \mathrm{m}^{3}$ were reported in the Warri Metropolis, Nigeria (Efe and Efe 2008). TSP levels were also measured in Benin City, another city with a tropical climate. Air quality monitoring was carried out with two different particulate matter samplers provided by the USA and the UK with assistance from the World Bank in 2004. Mean TSP levels measured at various sites using a gravimetric and light scattering method were 123.5 to 55.6 and 240 to $600 \mu \mathrm{g} / \mathrm{m}^{3}$, respectively (Ukpebor et al. 2006).

Linden et al. (2012) recently carried out field studies to analyze the spatial and temporal variability of air pollution and climate in Ouagadougou, Burkina Faso, focusing on the relationship between atmospheric stability and pollutant levels. $\mathrm{PM}_{10}$ and $\mathrm{PM}_{1}$ levels were substantially higher during highly stable compared to moderately stable atmospheric conditions across selected locations with various land cover, land use, and traffic density. For instance, average urban $\mathrm{PM}_{10}$ was $162 \mu \mathrm{g} / \mathrm{m}^{3}$ during extremely stable conditions compared to $69 \mu \mathrm{g} / \mathrm{m}^{3}$ during moderately stable conditions. In an earlier study, Boman et al. (2009) reported an average $\mathrm{PM}_{2.5}$ of $86 \mu \mathrm{g} / \mathrm{m}^{3}$ in 2007 in Ouagadougou and observed higher PM levels during periods of high atmospheric stability when pollutant dispersion was minimal.

In the most extensive scientific study to date examining urban air quality in Africa, Dionisio and colleagues carried out particulate matter monitoring in Accra, Ghana, to examine the within-neighborhood spatial variability of PM concentrations in communities of varying socioeconomic status (Dionisio et al. 2010a, b). Mean annual particulate matter values across all traffic and residential sides, excluding days with the strongest Harmattan winds, ranged between 30 and $70 \mu \mathrm{g} / \mathrm{m}^{3}$ for $\mathrm{PM}_{2.5}$ and between 57 and $108 \mu \mathrm{g} / \mathrm{m}^{3}$ for $\mathrm{PM}_{10}$. PM variability was greater across neighborhoods than across traffic sites and the highest PM level was observed in a densely populated low-income neighborhood. Biomass fuel use, emissions from traffic, and re-suspension from unpaved roads were identified as key determinants in the observed variability (Dionisio et al. 2010a).

\section{Eastern Africa}

Among the countries in Eastern Africa for which studies were identified, the highest PM levels were reported in Kenya. Tanzania was the country with lowest recorded mean PM levels that were below or only slightly exceeding the 24$\mathrm{h} \mathrm{PM}_{2.5}$ and $\mathrm{PM}_{10}$ guidelines, respectively.

Gatebe et al. (1996) carried out TSP measurements in Nairobi, Kenya, at the Meteorological Department Headquarters located in a suburban area $5 \mathrm{~km}$ north of the city center. They reported TSP ranging between 30 and $80 \mu \mathrm{g} / \mathrm{m}^{3}$ between December 1993 and October 1994. Subsequently, Odhiambo et al. (2010) collected $\mathrm{PM}_{10}$ samples at a busy highway site in Nairobi. Mean $\mathrm{PM}_{10}$ was $239 \mu \mathrm{g} / \mathrm{m}^{3}$, measured once a week for $8 \mathrm{~h}$ during a 3month period in 2003. More recently, Kinney et al. (2011) reported mean 11-h average (0730-1830 hours) $\mathrm{PM}_{2.5}$ concentrations between 58.1 and $98.1 \mu \mathrm{g} / \mathrm{m}^{3}$ at four traffic sites in July 2009. In this study, PM levels were measured using portable filter-based air samplers. Horizontal and vertical dispersion data showed rapid decrease in $\mathrm{PM}_{2.5}$ concentrations with increasing distance from the roadways, providing evidence for the traffic 
emissions as the primary source. The study also reported a 24-h mean $\mathrm{PM}_{2.5}$ urban background value of $34 \mu \mathrm{g} / \mathrm{m}^{3}$ from the roof of a building at the University of Nairobi, provided by Johan Boman from Gothenburg University.

A pilot air pollution monitoring study was carried out in Addis Ababa, Ethiopia, during the dry season of 2004 to obtain a snapshot of local air quality (Etyemezian et al. 2005). Twenty-four-hour $\mathrm{PM}_{10}$ concentrations ranged from 35 to $97 \mu \mathrm{g} / \mathrm{m}^{3}$ across 12 sampling sites around the city.

Several PM monitoring studies have been carried out in Tanzania. Hourly average TSP concentrations at 11 different traffic sites in Dar es Salaam ranged from 98 to $1161 \mu \mathrm{g} / \mathrm{m}^{3}$ in 2002 (Jackson 2005). Samples were collected for $1 \mathrm{~h}$ using manual air samplers. The study also reported that higher TSP levels were associated with increased traffic flow rates.

Jonsson et al. (2004) performed field campaigns during the rainy and dry seasons in Dar es Salaam, Tanzania, to determine the seasonal influence on the relationship between urban climate and air pollution. The article reported 12-h TSP mean levels of $40 \mu \mathrm{g} / \mathrm{m}^{3}$ at urban and $20 \mu \mathrm{g} / \mathrm{m}^{3}$ at rural sites, respectively. Similarly to the studies in Burkina Faso discussed previously (Boman et al. 2009), higher levels of air pollution were observed during stable atmospheric conditions.

Mkoma and colleagues carried out several PM campaigns in Tanzania (Mkoma et al. 2009, 2010). They reported PM $_{10}$ 24-h values of 76 and $52 \mu \mathrm{g} / \mathrm{m}^{3}$ and $\mathrm{PM}_{2.5}$ 24-h values of 26 and $19 \mu \mathrm{g} / \mathrm{m}^{3}$ for the 2005 dry and 2006 wet seasons, respectively.

Domestic use of biomass, which is the major energy source for cooking in Tanzania (Kilabuko et al. 2007) has substantial impact on outdoor PM levels. In a study of the association between exposure to biomass fuel smoke and acute respiratory infections in the Bagamoyo district in Tanzania, Kilabuko and colleagues recorded mean outdoor $\mathrm{PM}_{10}$ levels of $40.1 \mu \mathrm{g} / \mathrm{m}^{3}$ which increased to $428.6 \mu \mathrm{g} / \mathrm{m}^{3}$ during periods of cooking (Kilabuko and Nakai 2007).

Finally, Kuvarega and Taru (2008) reported TSP, PM $_{10}$, and $\mathrm{PM}_{2.5}$ levels of 106,60 , and $41 \mu \mathrm{g} / \mathrm{m}^{3}$ in Harare, Zimbabwe. Sampling took place at a school site between July and December of 2002.

\section{Southern Africa}

South Africa has an operating PM monitoring network, including monitoring stations for $\mathrm{PM}_{2.5}$ and $\mathrm{PM}_{10}$ in Cape Town and Johannesburg. To date, however, data have only been published in governmental reports which were beyond the scope of this article. $\mathrm{A} \mathrm{PM}_{10}$ and $\mathrm{PM}_{2.5}$ particulate monitoring campaign was carried out in winter of 1997 in Qalabotjha, South Africa, to evaluate potential air quality improvement in residential areas resulting from switching from D-grade domestic coal to low-smoke fuels (Engelbrecht et al. 2001). The study found a reduction in PM levels in the course of phasing on of the low-smoke fuels. Overall, 24-h urban concentrations for $\mathrm{PM}_{2.5}$ were between 71 to $93 \mu \mathrm{g} / \mathrm{m}^{3}$ and for $\mathrm{PM}_{10}$ between 77 and $112 \mu \mathrm{g} / \mathrm{m}^{3}$ over a 30-day period. More recently, Worobiec et al. (2011) reported 24-h average $\mathrm{PM}_{2.5}$ of $65 \mu \mathrm{g} / \mathrm{m}^{3}$ in Bethlehem, South Africa, and concluded that $\mathrm{PM}_{1}$ particles were the major contributor to $\mathrm{PM}_{20}$ during evening biomass burning. Elemental analysis of $\mathrm{PM}_{2.5}$ collected in Skukuza, South Africa, as a part of the SAFARI 2000 dry season campaign also identified biomass burning as the major contributor (Maenhaut et al. 2002).

\section{Discussion}

Routine PM monitoring does not exist in most African cities and only a few studies have reported annual mean levels of $\mathrm{PM}_{10}$ and $\mathrm{PM}_{2.5}$. In most of the studies we found, monitoring campaigns were carried out for less than a year and often for various durations of less than $24 \mathrm{~h}$ per day. In addition, diverse air monitoring methods were employed, making comparison of the data across studies challenging. Nonetheless, since our major objective was to access how the various reported values compare to WHO guidelines for particulate matter, the data we were able to identify are sufficient to provide a snapshot of urban PM pollution across the continent.

The influence that Africa's diverse climate exerts on particulate air pollution and the pronounced seasonal fluctuations in PM pollution in many African countries should be considered in developing strategies for air pollution control on the continent. A better understanding of the interplay of climatic and geographic factors with human activities would also be especially valuable. In particular, more systematic information of PM sources, which tend to be different in African cities compared to, for example, American or European cities, would greatly facilitate the development of pollution mitigation strategies. For example, re-suspended road dust from unpaved roads is one of the main PM sources, especially in urban areas (Arku et al. 2008; Boman et al. 2009; Dionisio et al. 2010a; Eliasson et al. 2009; Etyemezian et al. 2005; Lindén et al. 2012; Zghaid et al. 2009).

The major anthropogenic air pollution sources in African cities include emissions from waste and biomass burning for household and commercial needs, industrial activities, and emissions from vehicles as well as suspension from unpaved roads. Vehicle ownership is rapidly increasing in many African countries and is of particular concern for air quality in urban areas. Many of the newly imported vehicles are old and poorly maintained due to lacking or difficult to enforce regulatory standards (Lagarde 2007). Additionally, many cities are growing without accompanying transportation infrastructure and services, leading to transportation systems characterized by severe traffic congestion, lack of accessible public transport options, as well as bike and pedestrian lanes 


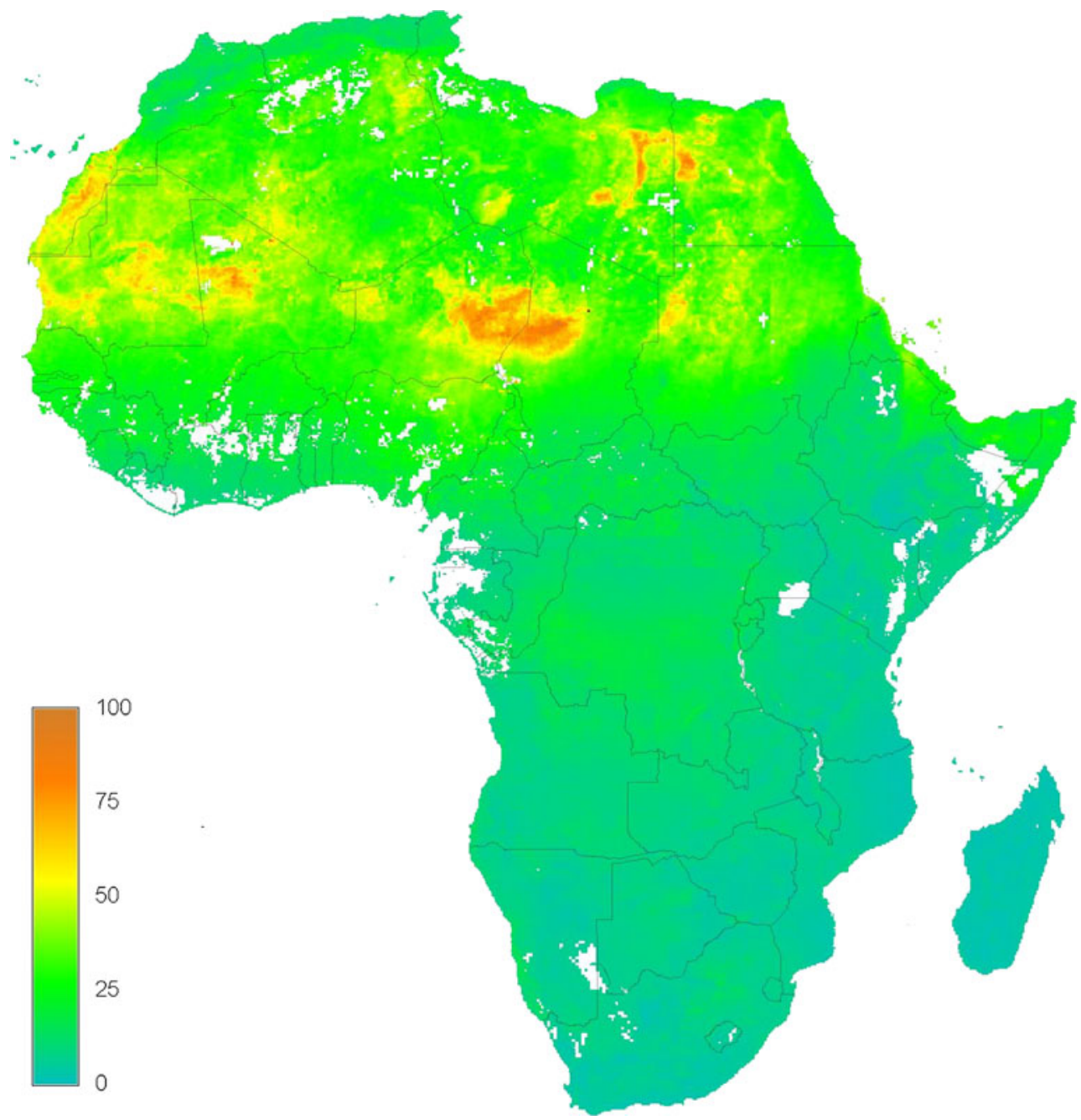

Fig. 4 Satellite-derived estimates of average $\mathrm{PM}_{2.5}$ concentrations between 2001 and 2006 (locations with less than 50 satellite measurements indicated in white) on the African continent. Source Van Donkelaar et al. 2010

(Republic of Kenya 2004; Aligula et al. 2005). The current trend of massive road expansion may be welcomed, but at the same time it seems to primarily be opening up space for more cars on bigger roads, and without appropriate transport policies, these roads are likely to quickly become congested again (Kinney et al. 2011; Klopp 2012).

Transportation and land use planning play key roles in determining urban population health outcomes (Woodcock et al. 2009). Given the WHO projections that Africa will face an increasing burden from cardiovascular disease and diabetes (De-Graft Aikins et al. 2010), improvements in urban air quality represent an important public health priority. A study which estimated the health effects of alternative urban land transport scenarios for London, UK, and Delhi, India, found that active transport options can yield large health gains (Woodcock et al. 2009).

Further, while adverse health effects of PM have been well established in studies in developed countries, the issue has not received appropriate consideration in many African countries, where air quality programs have often been stalled or discontinued in recent years. Given projections that the majority of global population growth between now and 2050 will be concentrated in cities (Africa's urban population is projected to increase from 414 million to 1.265 billion between 2011 and 2050) (UN 2012), the lack of outdoor urban air quality data is particularly worrisome.

The findings from the recent study in Accra, Ghana, that indicate higher levels of air pollution in low socioeconomic status communities are consistent with those in developed countries (Dionisio et al. 2010b) and outline an important research gap. Further examination of the differences in PM pollution by socioeconomic status, particularly in countries with a high degree of socioeconomic segregation, would provide important insights about social and environmental determinants of health and well-being on the continent. 
PM concentration estimates from satellite-based aerosol observations that have recently become available may be particularly helpful in assessing outdoor air pollution in Africa. Van Donkelaar et al. (2010) estimated global ground-level $\mathrm{PM}_{2.5}$ concentrations on a $10 \times 10-\mathrm{km}$ grid for the period 2001-2006 using aerosol optical depth observations from NASA satellite instruments together with modelderived aerosol vertical distribution. This is a very useful new resource for evaluating PM pollution in regions where little or no monitoring data exist. Estimated long-term average $\mathrm{PM}_{2.5}$ levels were below $25 \mu \mathrm{g} / \mathrm{m}^{3}$ in most parts of Africa but were substantially higher in Northern Africa where concentrations of over $50 \mu \mathrm{g} / \mathrm{m}^{3}$ were estimated in many locations, presumably due to the influence of desert dust (Fig. 4). Although the spatial resolution of these data remains rather low for assessing urban air quality, it certainly holds promise as a supplement to ground measurements and in guiding future monitoring studies. Brauer et al. (2012) have recently utilized the methodology of van Donkelaar and colleagues in deriving the PM estimates that are being used in assessing the global burden of diseases attributable to outdoor air pollution (Brauer et al. 2012).

\section{Conclusion and recommendations}

We provided an overview of PM air monitoring studies in Africa in order to assess how reported data compare to international air quality guidelines. Our review identified few examples of long-term, systematic monitoring of PM in African cities. Although monitoring methods and durations often do not enable direct comparisons with international guidelines, available data suggest that $\mathrm{PM}_{10}$ and $\mathrm{PM}_{2.5}$ levels exceeded, in many cases by several times, the WHO annual guidelines. The bulk of available data derives from short-term studies, which report PM levels that also exceed substantially the 24-h air quality guidelines in almost all instances.

There are insufficient data to track long-term temporal trends in PM levels. Our review highlights a need for further attention to assessing trends especially given the increasing motor vehicle traffic in recent years. $\mathrm{PM}_{10}$ levels in Africa are already substantially higher than levels in Europe and the Americas and are exceeded only in Southeast Asia, the Eastern Mediterranean ${ }^{2}$, and in low- and middle-income countries in the Western Pacific (WHO 2013).

In the process of this literature review, we identified publications in local African journals that were not well indexed and thus difficult to access by the international

\footnotetext{
${ }^{2}$ Morocco, Tunisia, Libya , Egypt, and Sudan, all in the Northern African UN subregion, are in the WHO Eastern Mediterranean region.
}

research community. Governmental monitoring data were also rarely accessible online. Building an air quality information system for publishing and sharing of monitoring data across academic and governmental and other institutions would greatly facilitate the characterization of particulate matter pollution on the continent as well as the planning and implementation of future studies. A publicly available information system would enable the assessment of the health impacts of outdoor air pollution on rapidly growing African urban populations, the development of appropriate interventions to reduce the air quality-related health burden, as well as influence urban planning and policy decisions which impact air quality.

Many of the studies reviewed here were carried out via international collaborations. Further development of such collaborations, together with technology transfer to African institutions, may be highly effective for establishing sustainable air monitoring practices across the continent in the long run. Setting up and operating air monitoring networks is costly and logistically challenging, and thus will take time to become established. In the meantime, shorter term air monitoring studies will continue to be useful in the assessment of air pollution levels and associated health effects. To maximize their effectiveness, studies should employ consistent, standardized methods and reporting criteria. Meeting these conditions would help to build a high quality network of PM monitoring data in African cities, which, along with further data from satellite-based aerosol observations, could go a long way towards filling data gaps. Doing so will generate local air quality and health findings of direct value in policy development.

Acknowledgments Support for this work has been provided by the Earth Institute at Columbia University. We thank Dr. Dieter Schwela at the Stockholm Environment Institute for providing valuable feedback on an early draft of this paper. We also thank the reviewers for their helpful comments.

\section{References}

Abu-Allaban M, Lowenthal DH, Gertler AW, Labib M (2007) Sources of $\mathrm{PM}_{10}$ and $\mathrm{PM}_{2.5}$ in Cairo's ambient air. Environ Monit Assess 133(1-3):417-425

Adeleke MA, Bamgbose JT, Oguntoke O, Itua EO, Bamgbose O (2011) Assessment of health impacts of vehicular pollution on occupationally exposed people in Lagos metropolis, Nigeria. Trace Elem Electrolytes 28(2):128-133

Aligula EM, Abiero-Gairy Z, Mutua J, Owegi F, Osengo C, Olela R (2005) Urban public transport patterns in Kenya: a case study of Nairobi City. Special report number 7. Kenya Institute for Public Policy Research and Analysis, Nairobi, Kenya.

Ali-Khodja H, Belaala A, Demmane-Debbih W, Habbas B, Boumagoura N (2008) Air quality and deposition of trace elements in Didouche Mourad, Algeria. Environ Monit Assess 138(13):219-231 
Aoudia MT, Boukadoum A (2005) Réseau de surveillance de la qualité de l'air en zone urbaine: Le cas de l'agglomération d'Alger [Monitoring network of the quality of air in urban areas: the case of the town of Algiers]. Pollut Atmosphérique 186:247-254

Arku RE, Vallarino J, Dionisio KL, Willis R, Choi H, Wilson JG, Hemphill C, Agyei-Mensah S, Spengler JD, Ezzati, M (2008) Characterizing air pollution in two low-income neighborhoods in Accra, Ghana. Sci Total Environ 402(2-3):217-231

Azri C, Maalej A, Medhioub K, Rosset R (2007) Evolution of atmospheric pollutants in the city of Sfax (Tunisia) (October 1996-June 1997). Atmosfera 20(3):223-246

Bailis R, Ezzati M, Kammen DM (2005) Mortality and greenhouse gas impacts of biomass and petroleum energy futures in Africa. Science 308(5718):98-103

Barnes DF, Krutilla K, Hyde WF (2005) The urban household energy transition: social and environmental impacts in the developing world. Resources for the Future, Washington, DC

Baumbach G, Vogt U, Hein KRG, Oluwole AF, Ogunsola OJ, Olaniyi HB, Akeredolu FA (1995) Air pollution in a large tropical city with a high traffic density - results of measurements in Lagos, Nigeria. Sci Total Environ 169:25-31

Boman J, Linden J, Thorsson S, Holmer B, Eliasson I (2009) A tentative study of urban and suburban fine particles $\left(\mathrm{PM}_{2.5}\right)$ collected in Ouagadougou, Burkina Faso. X-Ray Spectrom 38:354-362

Boutayeb A (2006) The double burden of communicable and noncommunicable diseases in developing countries. Trans Royal Soc Trop Med Hyg 100(3):191-199

Brauer M, Amann M, Burnett RT, Cohen A, Dentener F, Ezzati M, Henderson SB, Krzyzanowski M, Martin RV, van Dingenen R, van Donkelaar A, Thurston GD (2012) Exposure assessment for estimation of the global burden of disease attributable to outdoor air pollution. Environ Sci Technol 46(2):652-660

Chimidza S, Moloi K (2000) Identification of sources of aerosol particles in three locations in eastern Botswana. J Geophys Res D: Atmos 105(D14):811-818

Cohen AJ, Ross Anderson H, Ostro B, Pandey KD, Krzyzanowski M, Kunzli N, Gutschmidt K, Pope A, Romieu I, Samet JM, Smith K (2005) The global burden of disease due to outdoor air pollution. J Toxicol Environ Health Part A 68(13-14):1301-1307

De-Graft Aikins A, Unwin N, Agyemang C, Allotey P, Campbell C, Arhinful D (2010) Tackling Africa's chronic disease burden: from the local to the global. Glob Heal 6:5

Dionisio KL, Arku RE, Hughes AF, Jose Vallarin O, Carmichael H, Spengler JD, Agyei-Mensah S, Ezzati M (2010a) Air pollution in Accra neighborhoods: spatial, socioeconomic, and temporal patterns. Environ Sci Technol 44(7):2270-2276

Dionisio KL, Rooney MS, Arku RE, Friedman AB, Hughes AF, Vallarino J, Agyei-Mensah S, Spengler JD, Ezzati M (2010b) Within-neighborhood patterns and sources of particle pollution: mobile monitoring and geographic information system analysis in four communities in Accra, Ghana. Environ Heal Perspect 118(5):607-613

Dockery DW, Pope AC, Xu X, Spengler JD, Ware JH, Fay ME, Ferris BJ, Speizer FE (1993) An association between air pollution and mortality in six US cities. N Engl J Med 329:1753-1759

Dominici F, Peng R, Bell M, Pham L, Mcdermott A, Zeger S, Samet J (2006) Fine particulate air pollution and hospital admission for cardiovascular and respiratory diseases. JAMA 295(10):1127-1134

Efe SI, Efe AT (2008) Spatial distribution of particulate matter $\left(\mathrm{PM}_{10}\right)$ in Warri metropolis, Nigeria. Environmentalist 28(4):385-394

Eliasson I, Jonsson P, Holmer B (2009) Diurnal and intra-urban particle concentrations in relation to windspeed and stability during the dry season in three African cities. Environ Monit Assess 154(14):309-324
Engelbrecht JP, Swanepoel L, Chow JC, Watson JG, Egami RT (2001) $\mathrm{PM}_{2.5}$ and $\mathrm{PM}_{10}$ concentrations from the Qalabotjha. Low-smoke fuels macro-scale experiment is South Africa. Environ Monit Assess 69(1):1-15

Engelstaedtera S, Tegenb I, Washingtona R (2006) North African dust emissions and transport. Earth Sci Rev 79(1-2):73-100

Etyemezian VE, Tesfaye M, Yimer A, Chow JC, Mesfin D, Nega T, Nikolich G, Watson JG, Wondmagegn M (2005) Results from a pilot-scale air quality study in Addis Ababa, Ethiopia. Atmos Environ 39:7849-7860

Fotso JC (2007) Urban-rural differentials in child malnutrition: trends and socioeconomic correlates in sub-Saharan Africa. Health Place 13(1):205-223

Gargouri I, Rebaï A, Khadhraoui M, Kallel M, Jmal-Hammammi K, Masmoudi M, Elleuch B, Haguenoer J (2006) Impact sanitaire des variations quotidiennes de la pollution atmosphérique urbaine: étude de faisabilité dans laville de Sfax (Tunisie). [Health impact of daily variations in urban air pollution: feasibility study in Sfax (Tunisia)]. Environ Risques et Santé 5(6):467-475

Gatebe CK, Kinyua AM, Mangala MJ, Kwach R, Njau LN, Mukolwe EA, Maina DM (1996) Determination of suspended particulates matter of major significance to human health using nuclear techniques in Kenya. J Radioanal Nucl Chem 203(1):125-134

Giannini A, Biasutti M, Sobel AH, Held IM (2008) A global perspective on African climate. Clim Chang 90:359-383

Health Effects Institute (HEI) (2000) Reanalysis of the Harvard Six Cities Study and the American Cancer Society study of particulate air pollution and mortality: a special report of the Institute's particle epidemiology reanalysis project. Health Effects Institute, Cambridge

Jackson MM (2005) Roadside concentration of gaseous and particulate matter pollutants and risk assessment in Dar es Salaam, Tanzania. Environ Monit Assess 104(1-3):385-407

Jonsson P, Bennet C, Eliasson I, Selin Lindgren E (2004) Suspended particulate matter and its relations to the urban climate in Dar es Salaam, Tanzania. Atmos Environ 38(25):4175-4181

Kilabuko JH, Nakai S (2007) Effects of cooking fuels on acute respiratory infections in children in Tanzania. IntJ Environ Res Public Health 4(4):283-288

Kilabuko JH, Matsuki H, Nakai S (2007) Air quality and acute respiratory illness in biomass fuel using homes in Bagamoyo, Tanzania. Int J Environ Res Public Health 4(1):39-44

Kinney PL, Gichuru MG, Volavka-Close N, Ngo N, Ndiba PK, Law A, Gachanja A, Gaita SM, Chillrud SN, Sclar E (2011) Traffic impacts on $\mathrm{PM}(2.5)$ air quality in Nairobi, Kenya. Environ Sci Policy 14(4):369-378

Klopp JM (2012) Towards a political economy of transportation policy and practice in Nairobi. Urban Forum 23(1):1-21

Krewski D, Burnett RT, Goldberg MS, Hoover K, Siemiatycki J, Abrahamowicz M, White WH (2004) Validation of the Harvard Six Cities Study of particulate air pollution and mortality. N Engl J Med 350(2):198-199

Kuvarega AT, Taru P (2008) Ambiental dust speciation and metal content variation in TSP, $\mathrm{PM}_{10}$ and $\mathrm{PM}_{2.5}$ in urban atmospheric air of Harare (Zimbabwe). Environ Monit Assess 144(1-3):1-14

Kyobutungi C, Ziraba AK, Ezeh A, Yé Y (2008) The burden of disease profile of residents of Nairobi's slums: results from a Demographic Surveillance System. Pop Health Metr 6:1

Laakso L, Laakso H, Aalto PP, Keronen P, Petäjä T, Nieminen T, Pohja T, Siivola E, Kulmala M, Kgabi N, Molefe M, Mabaso D, Phalatse D, Pienaar K, Kerminen V (2008) Basic characteristics of atmospheric particles, trace gases and meteorology in a relatively clean Southern African Savannah environment. Atmos Chem Phys Discuss $8(2): 6313-6353$

Lagarde E (2007) Road traffic injury is an escalating burden in Africa and deserves proportionate research efforts. PLoS Med 4(6):e170 
Laid Y, Atek M, Oudjehane R, Filleul L, Baough L, Zidouni N, Boughedaoui M, Tessier JF (2006) Health effects of $\mathrm{PM}_{10}$ air pollution in a low-income country: the case of Algiers. IntJ Tuberc Lung Dis 10(12):1406-1411

Lindén J, Boman J, Holmera B, Thorssona S, Eliasson I (2012) Intraurban air pollution in a rapidly growing Sahelian City. Environ Int 40:51-62

Maenhaut W, Schwarz J, Cafmeyer J, Annegarn HJ (2002) Study of elemental mass size distributions at Skukuza, South Africa, during the SAFARI 2000 dry season campaign. Nucl Instrum Methods Phys Res B 189:254-258

Mkoma SL, Maenhaut W, Chi X, Wang W, Raes N (2009) Characterisation of $\mathrm{PM}_{10}$ atmospheric aerosols for the wet season 2005 at two sites in East Africa. Atmos Environ 43(3):631-639

Mkoma SL, Chi X, Maenhaut W (2010) Characteristics of carbonaceous aerosols in ambient $\mathrm{PM}_{10}$ and $\mathrm{PM}_{2.5}$ particles in Dar es Salaam, Tanzania. Sci Total Environ 408(6):1308-1314

Nyanganyuraa D, Maenhaut W, Mathuthu M, Makarau A, Meixner FX (2007) The chemical composition of tropospheric aerosols and their contributing sources to a continental background site in northern Zimbabwe from 1994 to 2000. Atmos Environ 41(12):2644-2659

Odhiambo GO, Kinyua AM, Gatebe CK, Awange J (2010) Motor vehicles air pollution in Nairobi, Kenya. Res J Environ Earth Sci 2(4):178-187

Omran AR (1971) The epidemiological transition: a theory of the epidemiology of population change. Milbank Memorial Fund Q 49(4):509-538

Pearson JF, Bachireddy C, Shyamprasad S, Goldfine AB, Brownstein JS (2010) Association between fine particulate matter and diabetes prevalence in the U.S. Diabetes Care 33(10):2196-2201

Pope CA, Dockery DW (2006) Health effects of fine particulate air pollution: lines that connect. J Air Waste Manag Assoc 56(6):709 742

Pope CA, Thun MJ, Namboodiri MM, Dockery DW, Evans JS, Speizer FE, Heath CW (1995) Particulate air pollution as a predictor of mortality in a prospective study of US adults. Am J Respir Crit Care Med 151:669-674

Republic of Kenya (2004) Recommendations on integrated national transport policy: moving a working nation. Ministry of Transport, Nairobi, Kenya

Robaa SM (2003) Urban-suburban/rural differences over greater Cairo, Egypt. Atmosfera 16:157-171

Safar Z, Labib MW (2010) Assessment of particulate matter and lead levels in the Greater Cairo area for the period 1998-2007. J Adv Res 1(1):53-63

Schwela D (2006) Review of urban air quality in sub-Saharan Africa region-air quality profile of sub-Saharan African (SSA) countries. The World Bank

Sclar ED, Garau P, Carolini G (2005) The 21st century health challenge of slums and cities. Lancet 365(9462):901-903

Sinha P, Hobbs PV, Yokelson RJ, Bertschi IT, Blake DR, Simpson IJ, Gao S, Kirchstetter TW, Novakov T (2003) Emissions of trace gases and particles from savanna fires in southern Africa. J Geophys Res 108(D13):8487

Turner M, Krewski D, Pope CA, Chen Y, Gapstur S, Thun M (2011) Long-term ambient fine particulate matter air pollution and lung cancer in a large cohort of never-smokers. Am J Respir Crit Care Med 184(12):1374-1381

Ukpebor EE, Ukpebor JE, Oviasogie PO, Odiase JI, Egbeme MA (2006) Field comparison of two total suspended particulates (TSP) samplers to assess spatial variation. Int J Environ Stud 63(5):567-577

United Nations (UN), Department of Economic and Social Affairs, Population Division (2011) World population prospects: the 2010 revision. Population Division of the Department of Economic and Social Affairs of the United Nations Secretariat, New York

United Nations (UN), Department of Economic and Social Affairs, Population Division (2012) World urbanization prospects, the 2011 revision: highlights. United Nations (UN), Department of Economic and Social Affairs, Population Division, New York

Van Donkelaar A, Martin RV, Brauer M, Kahn R, Levy R, Verduzco C, Villeneuve PJ (2010) Global estimates of ambient fine particulate matter concentrations from satellite-based aerosol optical depth: development and application. Environ Heal Perspect 118(6):847-855

Volavka-Close N, Sclar ED (2010) Improving population health in a rapidly urbanizing world. In: Vlahov D, Bouuford JI, Pearson C, Norris L (eds) Urban health; global perspectives. Jossey Bass, San Francisco, pp 453-467

Woodcock J, Edwards P, Tonne C, Armstrong BG, Ashiru O, Banister D, Beevers S, Chalabi Z, Chowdury Z, Cohen A, Franco OH, Haines A, Hickman R, Lindsay G, Mittal I, Mohan D, Tiwari G, Woodward A, Roberts I (2009) Public health benefits of strategies to reduce greenhouse-gas emissions: urban land transport. Lancet 374(9705):1930-1943

World Health Organization (WHO) (2006) Air quality guidelines, global update 2005. WHO, Geneva

World Health Organization (WHO) (2013) Public Health and Environment (PHE). Database: outdoor air pollution in cities. http://www.who.int/phe/health_topics/outdoorair/databases/en/. Accessed 6 Jan 2013

Worobiec A, Potgieter-Vermaak S, Berghmans P, Winkler H, Burger R, Grieken R (2011) Air particulate emissions in developing countries: a case study in South Africa. Anal Lett 44(11):1907-1924

Zakey AS, Abdel-Wahab MM, Pettersson JBC, Gatari MJ, Hallquist M (2008) Seasonal and spatial variation of atmospheric particulate matter in a developing megacity, the Greater Cairo, Egypt. Atmosfera 21(2): 171-189

Zghaid M, Noack Y, Bounakla M, Benyaich F (2009) Pollution atmosphérique particulaire dans la ville de Kenitra (Maroc) [Atmospheric particulate pollution in Kenitra (Morocco)]. Poll Atmos 51(203):313-324

Zulu EM, Beguy D, Ezeh AC, Bocquier P, Madise NJ, Cleland J, Falkingham J (2011) Overview of migration, poverty and health dynamics in Nairobi City's slum settlements. J Urban Health: Bull NY Acad Med 28(Suppl 2):S185-S199 